\title{
Retinal vascular impairment in patients newly diagnosed with obstructive sleep apnea syndrome
}

\author{
Tomás Loureiro, ${ }^{1}$ Sandra Rodrigues-Barros, ${ }^{1}$ Diogo Lopes, ${ }^{1}$ Ana Rita Carreira, ${ }^{1}$ Ricardo Gomes, ${ }^{2}$ Nadine Marques, ${ }^{1}$ \\ Paula Telles, ${ }^{2}$ Ana Vide Escada, ${ }^{2}$ Nuno Campos ${ }^{1}$
}

${ }^{1}$ Ophthalmology Department; ${ }^{2}$ Pneumology Department of Hospital Garcia de Orta, Almada, Portugal

Background: To evaluate retinal morphological and vascular parameters in patients recently diagnosed with obstructive sleep apnea syndrome (OSAS) and determine the correlation between retinal vascular density and the severity of OSAS.

Methods: We performed a retrospective study on the retinal vasculature of patients with OSAS and age-match healthy controls. OSAS was confirmed by full-night cardiorespiratory polygraphy. Patients were divided into three groups according to disease severity given by apnea-hypopnea index (AHI) i.e., mild, moderate or severe. Retinal thicknesses and vascular density were compared among groups, for both the macula and optic disc. Correlation between vascular density and clinical features were also assessed.

Results: The study included 30 eyes of patients with OSAS and 12 controls. No differences were found regarding retinal thickness in both the macula and the optic disc between OSAS patients and controls. In contrast, significant differences were found in the peripapillary vessel density between groups versus control patients. The greatest difference being between severe OSAS and controls $(49.4 \% \pm 2.1$ versus $40.4 \% \pm 4.2$ respectively, $\mathrm{p}=0.01)$. Peripapillary vessel density was found to significantly and negatively correlate with AHI ( $\mathrm{p}=0.02 ; \mathrm{r}=-0.74)$ and directly correlate with the lowest percutaneous oxygen saturation $(\mathrm{p}=0.02 ; \mathrm{r}=0.58)$.

Conclusions: This study indicates that OSAS is associated with retinal microvasculature impairment, that seems to mainly affect the optic disc. This suggests that microvascular damage increases with the increasing severity of OSAS. As such, prospective trials are needed to clarify if this vascular peripapillary damage precedes glaucomatous optic neuropathy in OSAS patients.

Key words: OSAS; glaucoma; oct-a; retinal density.

Correspondence: Tomás de Oliveira Loureiro, Ophthalmology Department, Hospital Garcia de Orta, Avenida Torrado da Silva, 2805-267 Almada, Portugal. Tel.+351.913.513175. E-mail: loureiro.tomas@gmail.com

Contributions: All the authors made a substantive intellectual contribution. All the authors have read and approved the final version of the manuscript and agreed to be accountable for all aspects of the work.

Conflict of interest: The authors declare that they have no competing interests, and all authors confirm accuracy. Availability of data and materials: All data generated or analyzed during this study are included in this published article.

Ethics approval: Obtained from the institutional Research Committee of Hospital Garcia de Orta (Almada, Portugal). Written consent was not required due to retrospective nature of this study. However, patients gave their oral consent to participate and for publication. 


\section{Introduction}

Obstructive sleep apnea-hypopnea syndrome (OSAS) is a potentially serious condition and is the most common sleep breathing disorder with almost one billion people affected [1]. It is characterized by repetitive nocturnal oxygen desaturation [2]. OSAS has been revealed as a leading cause of several cardiovascular disorders. Accumulating evidence has linked OSAS to hypertension, type 2 diabetes mellitus, coronary artery disease, heart failure, and cardiac arrythmias [3].

OSAS has also been linked to some ophthalmological conditions. Specifically, studies have suggested that OSAS is a risk factor for anterior ischemic optic neuropathy, central serous retinopathy, retinal vein occlusion and both normal tension glaucoma (NTG) and open angle glaucoma (OAG) [4,5]. However, the specific mechanism for glaucomatous optic neuropathy in OSAS has not been established yet [6]. Some theories have suggested a vascular mechanism, with susceptible optic nerves being damaged due to poor blood flow. Some current studies have reported lower vascular densities, both in optic disc and in parafoveal area, in patients with OSAS $[7,8]$. However, these studies are few in number and most of them did not evaluate the patients from the earliest stages of disease and from before them having started nocturnal continuous positive airway pressure (CPAP) therapy, a treatment that could bias the vascular densities.

Therefore, we decided to evaluate retinal morphology and microcirculation in newly diagnosed OSAS patients not on CPAP therapy and to therefore better understand any correlation between vascular density and the severity of OSAS.

\section{Methods}

This is a single center retrospective study including patients above 18 years recently diagnosed with OSAS. Exclusion criteria were systemic conditions such as: hypertension, diabetes mellitus (DM), atherosclerosis and ophthalmological morbidities such as: refractive errors $>3$ diopters, media opacities, known history of glaucoma, age related macular degeneration, retinal vascular disease, optic neuropathy, and previous retinal surgery. All patients were assessed at the same week of diagnosis i.e., just before starting nocturnal CPAP therapy. The study was conducted by the principles of the Declaration of Helsinki and approval was obtained by institutional Research Committee of Hospital Garcia de Orta (Almada, Portugal). Written consent was not required due to retrospective nature of this study. Demographic and clinical data were collected, including age, gender, body mass index (BMI), and disease duration.

Polygraphic parameters were collected from a full-night cardiorespiratory polygraphy performed with portable Embletta MPR Sleep System device (Embletta, Broomfield, CO, USA). The apnea-hypopnea index (AHI, times/h) was calculated as the average number of apneas and hypopneas per hour of sleep. Apnea was defined as cessation of airflow for at least $10 \mathrm{~s}$ with effort to breathe. Hypopnea was a $\geq 30 \%$ reduction of airflow compared to the baseline for at least $10 \mathrm{~s}$ accompanied by an oxygen desaturation $>$ $3 \%$ or a "micro-arousal" [9]. OSAS severity was classified according to AHI. Mild OSAS for an AHI between 5-15, moderate for AHI 15-29 and severe for AHI $\geq 30$. Oxygen saturation $\left(\mathrm{SpO}_{2}\right)$ was measured by pulse oximetry and the lowest and mean oxygen saturations were taken into account. Oxygen desaturation index (ODI, episodes/h) was defined as the average number of desaturation episodes per hour of sleep. Desaturation episodes were described as a decrease in the mean oxygen saturation $\geq 4 \%$ for at least 10 s. Patients with ODI less than $20 / \mathrm{h}$ was considered "nondesaturating" and patients with ODI $\geq 20 / \mathrm{h}$ as desaturating. Cumulative time percentage with $\mathrm{SpO}_{2}<90 \%$ (CT90), defined as the cumulative time spent with $\mathrm{SpO}_{2}<90 \%$ during sleep, was also evaluated.

Patients were tested for the best corrected visual acuity (BCVA), intraocular pressure (IOP) with Goldmann applanation tonometer and refractive error. Slit lamp, gonioscopy and fundus examination was performed. Central corneal thickness (CCT) was measured with Pentacam $^{\circledR}$. Standard automated perimetry (SAP) was performed in every patient with Octopus 900 with EyeSuite software (Haag Streit International, G1 TOP test strategy). Mean defect (MD, dB) and loss of variance (sLV, dB) were registered. Macular and Optic Disc Spectral Domain Optical Coherence Tomography (SD-OCT) and Optical Coherence Tomography Angiography (Zeiss Cirrus HDOCT 5000 Model with Angioplex) were performed in all eyes after pupillary dilatation. $6 \times 6 \mathrm{~mm}$ retinal thickness macular and optic disc cubes and $3 \times 3 \mathrm{~mm}$ angiograms were obtained through the automatic segmentation algorithm. Image quality controls included a corrected foveal centering, the absence of artifacts and a signal strength $>7$. Mean retinal nerve fiber layer (RNFL), cup to disc ratio (c/d), rim area and mean ganglion cell complex (GCC) thickness were assessed. The macular retinal thicknesses were registered for each quadrant of parafovea and perifovea. The parafovea was defined as an annular region with an inner diameter of $0.6 \mathrm{~mm}$ and outer diameter of $2.5 \mathrm{~mm}$ centered on the FAZ. The perifovea is defined to be an annular region extending from the outer edge of the parafovea to an outer diameter of $5.5 \mathrm{~mm}$. Foveal avascular zone (FAZ), peripapillary and parafoveal superficial vascular density were automatically evaluated. Radial peripapillary capillary density (RPCD) concerns to the radial peripapillary plexus that runs superficially in the NFL. Superficial parafoveal vascular density (SVD) represents the complete vessels density of the superficial capillary plexus (SCP) in the parafovea. The vascular density is the percentage of signal positive pixels per total pixels in an area of interest. Only automatic superficial vascular densities were considered by the software. Perifoveal and deep plexus vascular densities required subjective measurements and for that reason, we chose to exclude them from this study.

The patients were then divided into three groups for comparative purposes according to their OSAS severity. Control healthy subjects had an AHI $<5 /$ hour and were recruited using the same exclusion criteria as OSAS. Presented results follow the order: controls, mild, moderate, and severe.

Statistical analysis was made by SPSS ${ }^{\mathrm{TM}}$ software v. 23.0. Continuous variables normality was checked by Shapiro-Wilk test. Kruskal-Wallis tests were used to compare the data among three groups with Bonferroni correction for multiple comparisons. MannWhitney tests were used to compare data between two groups when $\mathrm{p}<0.05$ on Kruskal-Wallis test. Spearman's correlation test was performed to assess correlations between polygraphy parameters and vessel density. Statistical significance was defined as $\mathrm{p}<0.05$.

\section{Results}

Our study included a total of 42 eyes from 21 patients: 12 control, 8 in the mild disease group, 10 in the moderate and 12 in the severe. Demographic and clinical data are presented in Table 1. There were 13 males $(62 \%)$ and $8(38 \%)$ females. Six patients had history of smoking.

We found no significant difference in the mean age or BMI 
among groups (age: $66.4 \pm 5.2$ vs $70.5 \pm 9.9$ vs $68 \pm 7.6$ vs $65.9 \pm 3.9$ years; $\mathrm{p}=0.3$ and BMI: $27.1 \pm 2.6$ vs $27 \pm 1.7$ v. $27.5 \pm 3.6$ vs $28.8 \pm 5.8$ $\left.\mathrm{Kg} / \mathrm{m}^{2} ; \mathrm{p}=0.8\right)$. We also found no significant difference among groups of the mean best corrected visual acuity $(\mathrm{p}=0.81)$. All eyes were found to have an intraocular pressure within the ranges of normality and no difference was observed among groups $(\mathrm{p}=0.47)$. Furthermore, all patients were found to have an iridocorneal angle grade as 3 or 4 (Schaffer's classification).

No statistically significant difference was found among groups when assessing central corneal thickness $(p=0.31$ ). In fact, all visual field examinations were found to be reliable. No visual defects were reported, and the mean defect $(\mathrm{p}=0.21)$ and loss of variance did not differ among groups $(\mathrm{p}=0.41)$.

The polygraphy data is presented in Table 2 . In the control group polygraphy data was not collected. The mean AHI data for OSAS was found to be $12 \pm 2.6$ episodes/hour in the mild group, $21.8 \pm 2.5$ in the moderate and $51.7 \pm 19.1$ in the severe. We found a correlation between severity of disease and the reduced levels of lowest oxygen saturation with the severe group showing the lowest values for lowest oxygen saturation i.e., $72.1 \pm 8.9 \%$. These differences were found to be statistically significant when compared to the moderate $(\mathrm{p}<0.01)$ and to mild $(\mathrm{p}<0.01)$ groups. Moreover, CT90\% decreased with increasing severity of disease $(p=0.02)$. The ODI was higher in the severe group $(42 \pm 25$ episodes/hour $)$ than in moderate $(p=0.04)$ and mild $(p=0.03)$ groups. Nine patients were considered as "desaturating" and six patients as "non-desaturating". The macular OCT and OCTA data are shown in Table 3. No significant differences were found among groups in retinal thicknesses, both in parafovea and in perifovea. Nor were any significant differences found among groups in the parafoveal superficial vascular density (38.1 \pm 3.2 vs $37.8 \pm 2.5$ vs $35.2 \pm 2.8$ vs $34.2 \pm 2.1 \mu \mathrm{m}$; $\mathrm{p}=0.34$, for control, mild, moderate and severe respectively).

The optic disc data are show in Table 4. No significant differences were found among groups when assessing the optic disc and neuroretinal rim areas, the RNFL and the cup to disc ratio. We found that the RPCD was highest in controls and then decreased in a manner that correlated with OSAS severity, leading to statistically significant differences when comparing control to medium $(49.4 \pm 2.1 \%$ vs $45.3 \pm 1.8 \%, \mathrm{p}=0.04)$ and control to severe cases $(49.4 \pm 2.1 \%$ vs $40.4 \pm 4.2 \%, \mathrm{p}=0.01)$. No significant differences were found between "desaturating" patients and "non-desaturating patients" regarding SVD $(\mathrm{p}=0.41)$ and $\operatorname{RCPD}(\mathrm{p}=0.21)$. However, significant inverse correlations were found between the AHI and $\operatorname{RCPD}(\mathrm{p}=0.02 ; \mathrm{r}=-0.74)$ and between CT90 and RCPD $(\mathrm{p}=0.01$; $\mathrm{r}=-0.67)$. A positive correlation between the lowest oxygen saturation and RCPD $(\mathrm{p}=0.02 ; \mathrm{r}=0.58)$ was registered. In contrast no correlation was found between RCPD and SVD for age $(p=0.45)$, ODI $(p=0.14)$, MD $(p=0.8)$ or $\operatorname{sLV}(p=0.7)$.

\section{Discussion}

Obstructive sleep apnea syndrome is a leading cause of several cardiovascular and ophthalmological diseases caused by

Table 1. Demographic and clinical data $(n=21)$.

\begin{tabular}{lcccccc} 
& Controls & Mild & Moderate & Severe & $\mathbf{p}^{*}$ & - \\
Number of patients & 6 & 4 & 5 & 6 & - & - \\
Gender, $\mathrm{n}$ & & & & 4 & - & - \\
$\quad$ Male & 3 & 3 & 3 & 2 & $65.9 \pm 3.9$ & 0.3 \\
$\quad$ Female & 3 & 1 & 2 & $68 \pm 7.6$ & $28.8 \pm 5.8$ & - \\
\hline Age, years & $66.4 \pm 5.2$ & $70.5 \pm 9.9$ & $27 \pm 1.7$ & $27.5 \pm 3.6$ & - \\
BMI $\left(\mathrm{kg} / \mathrm{m}^{2}\right)$ & $27.1 \pm 2.6$ & &
\end{tabular}

*Results of comparison of means among three groups with Kruskal-Wallis' corrected by Bonferroni; ${ }^{\circ}$ Results of comparison of means between two groups with Mann-Whitney's test; this test was performed when p-value was inferior to 0.05 on Kruskal-Wallis' corrected by Bonferroni; BMI, body mass index.

Table 2. Polygraphy data $(n=15)$.

\begin{tabular}{|c|c|c|c|c|c|}
\hline 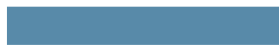 & Mild & Moderate & Severe & $\mathbf{p}^{*}$ & $\mathbf{p}^{\circ}$ \\
\hline $\mathrm{AHI}, / \mathrm{h}$ & $12 \pm 2.6$ & $21.8 \pm 2.5$ & $51.7 \pm 19.1$ & - & - \\
\hline Mean $\mathrm{O}_{2}$ saturation, $\%$ & $95.1 \pm 0.9$ & $93.7 \pm 1.3$ & $91.5 \pm 2.7$ & 0.32 & - \\
\hline $\begin{array}{l}\text { Lowest } \mathrm{O}^{2} \text { saturation, } \% \\
\text { Mild } v \text { moderate } \\
\text { Mild vs severe } \\
\text { Moderate } v \text { s severe }\end{array}$ & $89.3 \pm 2.7$ & $84.3 \pm 0.9$ & $72.1 \pm 8.9$ & 0.03 & $\begin{array}{c}- \\
0.4 \\
<0.01 \\
<0.01\end{array}$ \\
\hline $\begin{array}{l}\text { CT90 (\%) } \\
\quad \text { Mild vs moderate } \\
\text { Mild vs severe } \\
\text { Moderate } v s \text { severe }\end{array}$ & $0.51 \pm 0.12$ & $4.21 \pm 0.6$ & $21.2 \pm 4.1$ & 0.02 & $\begin{array}{c}- \\
0.3 \\
<0.01 \\
<0.01\end{array}$ \\
\hline $\mathrm{ODI}, / \mathrm{h}$ & $11 \pm 4$ & $16.5 \pm 1.3$ & $42 \pm 25$ & 0.03 & - \\
\hline $\begin{array}{l}\text { Mild } v s \text { moderate } \\
\text { Mild } v s \text { severe } \\
\text { Moderate } v s \text { severe }\end{array}$ & & & & & $\begin{array}{l}0.5 \\
0.03 \\
0.04\end{array}$ \\
\hline
\end{tabular}

*Results of comparison of means among three groups with Kruskal-Wallis' corrected by Bonferroni; ${ }^{\circ}$ results of comparison of means between two groups with Mann-Whitney's test; this test was performed when p was inferior to 0.05 on Kruskal-Wallis' corrected by Bonferroni; $\mathrm{AHI}$, apnea-hypopnea index; $\mathrm{CT} 90$ : cumulative time percentage with $\mathrm{SpO}_{2}<90 \%$; $\mathrm{O}_{2}$, oxygen; $\mathrm{ODI}$, oxygen desaturation index. 
microvascular impairment. Walsh and Montplaisir initially described the association between OSAS and glaucoma in 1982 and Mojon et al. published the first article reporting higher glaucoma prevalence amongst OSAS patients $[10,11]$. Accumulating evidence indicates that the prevalence of glaucoma and its progression are higher in OSAS patients [6]. Although the underlying mechanism of glaucomatous damage in OSAS patients is unclear, there are several potential explanations.

The mechanical theory suggests that IOP compresses the optic nerve causing glaucomatous damage. Indeed, some studies have revealed higher IOP in OSAS patients compared to controls [1214]. However, the literature contains conflicting data regarding changes in IOP in cases of OSAS. Some studies reported that the prevalence of glaucoma in OSAS is independent of IOP [15]. Bilgin et al. found an association between normal tension glaucoma and OSAS [16]. Shinmei et al. monitored IOP during sleep with wireless contact lens sensors and found a decrease in IOP during hypopneic and apneic events [17]. These studies suggest that elevated IOP might not be the only causative factor involved in the development of glaucomatous optic neuropathy, at least in the observed patients.
In our study, we found that all patients had normal IOP values and there was no difference among groups.

In contrast to the mechanical theory the vascular theory proposes that neuropathy develops as a result of vascular dysregulation, ischemia and abnormal perfusion pressure of optic nerve which may become sensitized and then damaged in these patients even with normal IOP values [18]. Abegão Pinto et al. was one of the first groups that tried to integrate vascular findings into glaucoma practice [19]. Using colour doppler they found that glaucoma patients had higher mean ocular perfusion pressures and lower retrobulbar velocities than controls. Later, Breda et al. reported that they found RPCD to be the best factor discriminating among different severities of glaucoma. Here, lower vascular densities accompanied the severity of disease, emphasizing the importance of vascular integrity in this disease [20]. The vascular impairment in OSAS was first studied in cerebral vessels [21]. Some studies showed that impairment of brain vascular system was correlated with AHI and oxygen saturation [22]. Coloma et al. reported a positive correlation between cerebral mean flow density and mean nocturnal oxygen saturation [23]. Considering these

Table 3. Macular OCT and OCTA data $(n=42)$.

\begin{tabular}{|c|c|c|c|c|c|c|}
\hline & Controls & Mild & Moderate & Severe & $\mathbf{p}^{*}$ & $\mathbf{p}^{\circ}$ \\
\hline Fovea, $\mu \mathrm{m}$ & $263.1 \pm 10.2$ & $267.1 \pm 5.1$ & $255.5 \pm 9.8$ & $267.6 \pm 30.7$ & 0.17 & - \\
\hline $\begin{array}{l}\text { Parafovea, } \mu \mathrm{m} \\
\quad \text { Inferior } \\
\text { Superior } \\
\text { Nasal } \\
\text { Temporal } \\
\end{array}$ & $\begin{array}{c}321.1 \pm 6.9 \\
324.5 \pm 9.2 \\
331.6 \pm 10.7 \\
318.4 \pm 9.2\end{array}$ & $\begin{array}{c}318.3 \pm 7.1 \\
324 \pm 10 \\
330.1 \pm 5.5 \\
315.7 \pm 10.8\end{array}$ & $\begin{array}{c}330.4 \pm 4.2 \\
332 \pm 4.9 \\
339.2 \pm 3.9 \\
324.7 \pm 2.4\end{array}$ & $\begin{array}{c}329.5 \pm 27.2 \\
334 \pm 26.9 \\
325.1 \pm 26.8 \\
315 \pm 35.3\end{array}$ & $\begin{array}{c}0.37 \\
0.5 \\
0.67 \\
0.68\end{array}$ & $\begin{array}{l}- \\
- \\
-\end{array}$ \\
\hline $\begin{array}{l}\text { Perifovea, } \mu \mathrm{m} \\
\quad \text { Inferior } \\
\text { Superior } \\
\text { Nasal } \\
\text { Temporal }\end{array}$ & $\begin{array}{l}267.2 \pm 9.1 \\
280.1 \pm 7.3 \\
283.4 \pm 6.2 \\
262.5 \pm 4.3\end{array}$ & $\begin{array}{c}269.1 \pm 8.5 \\
296.6 \pm 23.3 \\
287.4 \pm 11.7 \\
260.1 \pm 8\end{array}$ & $\begin{array}{c}276 \pm 7.5 \\
309.7 \pm 21.3 \\
300 \pm 5 \\
262.7 \pm 3\end{array}$ & $\begin{array}{l}269.7 \pm 15.7 \\
291.2 \pm 25.8 \\
298.5 \pm 21.1 \\
270.1 \pm 24.1\end{array}$ & $\begin{array}{l}0.34 \\
0.14 \\
0.22 \\
0.39\end{array}$ & $\begin{array}{l}- \\
- \\
-\end{array}$ \\
\hline $\mathrm{GCC}, \mu \mathrm{m}$ & $81 \pm 4.8$ & $81 \pm 4.8$ & $78.4 \pm 9.7$ & $79.1 \pm 3.8$ & 0.47 & - \\
\hline SVD, $\%$ & $38.1 \pm 3.2$ & $37.8 \pm 2.5$ & $35.2 \pm 2.8$ & $34.2 \pm 2.1$ & 0.34 & - \\
\hline
\end{tabular}

*Results of comparison of means among three groups with Kruskal-Wallis' corrected by Bonferroni; ${ }^{\circ}$ results of comparison of means between two groups with Mann-Whitney's test; this test was performed when p was inferior to 0.05 on Kruskal-Wallis' corrected by Bonferroni; GCC, ganglion cell complex; SVD, parafoveal superficial vascular density.

Table 4. Optic disc OCT and OCTA data $(n=42)$.

\begin{tabular}{|c|c|c|c|c|c|c|}
\hline & Controls & Mild & Moderate & Severe & $\mathbf{p}^{*}$ & $\mathbf{p}^{\circ}$ \\
\hline $\begin{array}{l}\text { RFNL, } \mu \mathrm{m} \\
\text { Mean } \\
\text { Inferior } \\
\text { Superior } \\
\text { Nasal } \\
\text { Temporal }\end{array}$ & $\begin{array}{c}90.1 \pm 6.1 \\
109.2 \pm 8.2 \\
116.3 \pm 11.2 \\
90 \pm 12.7 \\
60.1 \pm 11.7\end{array}$ & $\begin{array}{c}89 \pm 7.1 \\
102.3 \pm 15.3 \\
112.1 \pm 7.1 \\
92.4 \pm 18.1 \\
60.2 \pm 13.6\end{array}$ & $\begin{array}{c}92.2 \pm 13.1 \\
111.3 \pm 21.9 \\
105.5 \pm 7.1 \\
88.3 \pm 6.2 \\
55.1 \pm 13.3\end{array}$ & $\begin{array}{c}89.3 \pm 7.1 \\
111.6 \pm 14.1 \\
115.1 \pm 14.4 \\
84 \pm 8.2 \\
56.9 \pm 8.2\end{array}$ & $\begin{array}{l}0.47 \\
0.42 \\
0.23 \\
0.27 \\
0.69\end{array}$ & $\begin{array}{l}- \\
- \\
- \\
- \\
-\end{array}$ \\
\hline Area, $\mathrm{mm}^{2}$ & $1.6 \pm 0.2$ & $1.7 \pm 0.2$ & $1.8 \pm 0.1$ & $1.6 \pm 0.1$ & 0.32 & - \\
\hline Neuroretinal rim, $\mathrm{mm}^{2}$ & $1.3 \pm 0.3$ & $1.3 \pm 0.1$ & $1.4 \pm 0.1$ & $1.3 \pm 0.1$ & 0.34 & - \\
\hline $\mathrm{C} / \mathrm{D}$ & $0.46 \pm 0.3$ & $0.45 \pm 0.2$ & $0.47 \pm 0.1$ & $0.43 \pm 0.1$ & 0.94 & - \\
\hline $\begin{array}{l}\text { RPCD, } \% \\
\text { Control vs mild } \\
\text { Control vs moderate } \\
\text { Control } v \text { s severe } \\
\text { Mild } v s \text { moderate } \\
\text { Mild } v s \text { severe } \\
\text { Moderate } v s \text { severe } \\
\end{array}$ & $49.4 \pm 2.1$ & $46 \pm 1.1$ & $45.3 \pm 1.8$ & $40.4 \pm 4.2$ & 0.01 & $\begin{array}{l}0.06 \\
0.04 \\
0.01 \\
0.63 \\
0.02 \\
0.04 \\
\end{array}$ \\
\hline
\end{tabular}

*Results of comparison of means among three groups with Kruskal-Wallis' corrected by Bonferroni; ${ }^{\circ}$ results of comparison of means between two groups with Mann-Whitney's test; this test was performed when p was inferior to 0.05 on Kruskal-Wallis' corrected by Bonferroni; RFNL, retinal nerve fiber layer; C/D, cup to disc ratio; RPCD, radial peripapillary capillary density. 
findings, it is possible that the cerebral vascular impairment that occurs in OSAS, may also occur at the level of the microcirculation of the optic nerve. To our knowledge, there are few studies regarding retinal microvasculature in patients with OSAS, especially those at the earliest stages of disease.

In our study, we observed a significant decrease in RPCD with increasing severity of OSAS. RPCD was higher in controls than in moderate and severe groups, suggesting a vascular impairment in these patients. Although there was no statistically significant difference, the RPCD seemed to be lower in the mild group comparing to controls $(\mathrm{p}=0.06)$ and this lack of difference could be due to the small sample size. No significant differences were found in the parafoveal SVD. Yu et al. reported that retinal vessel densities in the parafoveal and peripapillary areas decreased with greater severity of OSAS, with more prominent decrease in the peripapillary area [7]. The vessels in the peripapillary area originate from central retinal artery (CRA) and also from short posterior ciliary arteries (SPCA) and are the source of nutrition to retinal ganglion cells. In macula the vessels originate only from CRA. Hayrech et al. reported that posterior ciliary arteries were more susceptible to high IOP effects than CRA, in patients with glaucoma [24]. Hosking et al. found an abnormal response to hypocapnia in SPCA but not in CRA [25]. These findings, taken together, suggest that ciliary vascular system may experience more damage in OSAS and supports the notion that the RPC is more prone to injury, corroborating our results.

Hypoxia is considered the trigger for microvascular disorders in OSAS patients. Potentially leading to ischemia around the optic nerve via several mechanisms as it promotes platelet activation and aggregation, hypercoagulability and decreases the synthesis of nitric oxide (NO) [26]. The most approximate scenario to study the impact of hypoxia was to compare the "desaturating" and "nondesaturating" patients. Moyal et al. [27] showed differences in RPCD between control and OSAS groups. Although our results showed a trend toward to be inferior in "non-desaturating" patients, it was not significant. However, we found a positive correlation between the lowest nocturnal oxygen saturation and RPCD what seems to support the role of hypoxia in optic nerve damage. Moreover, the inverse correlation between CT90 and OSAS severity could also highlight the role of chronic intermittent hypoxia and consequent vascular endothelial damage. CT90 was found to be positively correlated with serum $\mathrm{NO}$ concentration and with plasma endothelin-1 (ET-1). ET-1 contributes to endothelial dysfunction and enhances vasoconstriction which is the most probable mechanism of peripapillary vascular damage and further glaucoma development [28].

There is no consensus regarding RNFL damage in OSAS. Shiba et al. showed an inverse correlation between RNFL thickness and OSAS severity and Yu et al. showed that both moderate and severe OSAS were associated with a significant decrease in average RNFL thickness [29]. However, both Yu et al. and Moyal et al. found no differences in RNFL and macular thickness in OSAS patients [27]. Our study supports the findings of Yu et al. and Moyal et al. in that we too observed no significant differences between OSAS patients and controls. These findings suggest that in OSAS, as in other vascular retinopathies, vascular changes precede RNFL changes. As we only included newly diagnosed patients, that one would assume have only had a short duration of disease, we believe that morphological alterations may just become apparent later. We would also postulate that the conflicting data in the literature might be explained by the studies covering a wide range of disease duration and stages.
Functionally, we found no significant difference in visual field parameters (MD and sLV) between groups. Moyal et al. [27] found a negative correlation between AHI and visual field parameters. However, it did not seem to be reliable, and the authors believed it could be an incidental finding, due to lack of concentration or just the learning-curve phenomenon.

Our study is limited by the small sample, which reduces the significance of statistical analysis and also by the fact that we did not study the deep vascular plexus. However, others have shown that the deep vasculature is structurally normal in glaucoma [30]. In any case, our study differs from others, in regards to the inclusion of newly diagnosed patients which were not on CPAP therapy yet. A treatment that could mask any structural damage or vascular features was induced by disease or modified by oxygen therapy. At the same time, we only included patients with normal IOP, which could help to isolate the vascular damage in the role of glaucomatous damage in OSAS.

This study clearly suggests that the vascular peripapillary damage is seen in OSAS patients from the earliest stages. Despite our patients were recently diagnosed with OSAS, which may have precluded the observation of mounting vascular compromise, this could enhance the observation of the beginning of injury cycle. Moreover, we provide the basis for our ongoing long-term prospective clinical trial to understand the development of vascular damage preceding glaucomatous optic neuropathy in these patients.

\section{Conclusion}

Our study demonstrates that radial peripapillary capillary density is lower in newly diagnosed OSAS patients compared to controls and decreases as disease severity increases. The apneahypopnea index (AHI) and the lowest percutaneous oxygen saturation correlate the radial peripapillary capillary density.

As no morphological damage was observed in RNFL, a close follow up of these patients would help to understand the pathogenesis of this disease and the potential role of OCTA screening in the clinical care of OSAS patients.

\footnotetext{
Abbreviations

AHI: apnea-hypopnea index;

BVCA: best corrected visual acuity;

BMI: body mass index;

CCT: central corneal thickness;

CPAP: continuous positive airway pressure;

CT90: cumulative time percentage with $\mathrm{SpO}_{2}<90 \%$;

DM: diabetes mellitus;

IOP: intraocular pressure;

OSAS: obstructive sleep apnea syndrome;

OAG: open angle glaucoma;

OCT: optical coherence tomography;

OCTA: optical coherence tomography angiography;

ODI: oxygen desaturation index;

NTG: normal tension glaucoma;

RNFL: retinal nerve fiber layer;

RPCD: radial peripapillary capillary density;

SCP: superficial capillary plexus;

$\mathrm{SpO}_{2}$ : oxygen saturation;

SVD: superficial parafoveal vascular density.
} 


\section{References}

1. Benjafield AV, Ayas NT, Eastwood PR, Heinzer R, Ip MSM, Morrell MJ, et al. Estimation of the global prevalence and burden of obstructive sleep apnoea: a literature-based analysis. Lancet Respir Med 2019;7:687-98.

2. White DP. Pathophysiology of obstructive sleep apnoea. Thorax 1995;50:797-804.

3. Monahan K, Redline S. Obstructive sleep apnea and cardiovascular disease. In: CA Kushida, Editor. Encyclopedia of Sleep. Amsterdam: Eslevier; 2013. p. 360-4.

4. Santos M, Hofmann RJ. Ocular manifestations of obstructive sleep apnea. J Clin Sleep Med 201715;13:1345-8.

5. Huon LK, Liu SYC, Camacho M, Guilleminault C. The association between ophthalmologic diseases and obstructive sleep apnea: a systematic review and meta-analysis. Sleep Breath 2016;20:1145-54.

6. Liu S, Lin Y, Liu X. Meta-analysis of association of obstructive sleep apnea with glaucoma. J Glaucoma 2016;25:1-7.

7. Yu J, Xiao K, Huang J, Sun X, Jiang C. Reduced retinal vessel density in obstructive sleep apnea syndrome patients: An optical coherence tomography angiography study. Investig Ophthalmol Vis Sci 2017;58:3506-12.

8. Ucak T, Unver E. Alterations in parafoveal and optic disc vessel densities in patients with obstructive sleep apnea syndrome. J Ophthalmol 2020;2020:4034382.

9. Berry RB, Budhiraja R, Gottlieb DJ, Gozal D, Iber C, Kapur $\mathrm{VK}$, et al. Rules for scoring respiratory events in sleep: Update of the 2007 AASM manual for the scoring of sleep and associated events. J Clin Sleep Med 2012;8:597-619.

10. Walsh JT, Montplaisir J. Familial glaucoma with sleep apnoea: a new syndrome? Thorax 1982;37:845-9.

11. Mojon DS, Hess CW, Goldblum D, Fleischhauer J, Koerner F, Bassetti C, et al. High prevalence of glaucoma in patients with sleep apnea syndrome. Ophthalmology 1999;106:1009-12.

12. Casas P, Ascaso FJ, Vicente E, Tejero-Garcés G, Adiego MI, Cristóbal JA. Retinal and optic nerve evaluation by optical coherence tomography in adults with obstructive sleep apneahypopnea syndrome (OSAHS). Graefes Arch Clin Exp Ophthalmol 2013;251:1625-34.

13. Karakucuk S, Goktas S, Aksu M, Erdogan N, Demirci S, Oner A, et al. Ocular blood flow in patients with obstructive sleep apnea syndrome (OSAS). Graefes Arch Clin Exp Ophthalmol 2008;246:129-34.

14. Moghimi S, Ahmadraji A, Sotoodeh H, Sadeghniat K, Maghsoudipour M, Fakhraie G, et al. Retinal nerve fiber thickness is reduced in sleep apnea syndrome. Sleep Med 2013;14:53-7.

15. Chaitanya A, Pai VH, Mohapatra AK, Ve RS. Glaucoma and its association with obstructive sleep apnea: A narrative review. Oman J Ophthalmol 2016;9:125-34.

16. Bilgin G. Normal-tension glaucoma and obstructive sleep apnea syndrome: A prospective study. BMC Ophthalmol 2014;14:27.

17. Shinmei Y, Nitta T, Saito H, Ohguchi T, Kijima R, Chin S, et al. Continuous intraocular pressure monitoring during nocturnal sleep in patients with obstructive sleep apnea syndrome. Investig Ophthalmol Vis Sci 2016;57:2824-30.

18. Zengin MO, Tuncer I, Karahan E. Retinal nerve fiber layer thickness changes in obstructive sleep apnea syndrome: one year follow-up results. Int J Ophthalmol 2014;7:704-8.

19. Abegão Pinto L, Willekens K, Van Keer K, Shibesh A, Molenberghs G, Vandewalle E, et al. Ocular blood flow in glaucoma - the Leuven Eye Study. Acta Ophthalmol 2016;94:592-8.

20. Barbosa-Breda J, Andrade de Jesus D, Van Keer K, Nassiri V, Molenberghs G, Abegão Pinto L, et al. AngioOCT peripapillary microvascular density outperforms standard OCT parameters as a discriminant between different glaucoma severity levels-The Leuven Eye Study. Invest Ophthalmol Vis Sci 2018;59:4478.

21. Nasr N, Traon AP Le, Czosnyka M, Tiberge M, Schmidt E, Larrue V. Cerebral autoregulation in patients with obstructive sleep apnea syndrome during wakefulness. Eur J Neurol 2009;16:386-91.

22. Baril AA, Gagnon K, Arbour C, Soucy JP, Montplaisir J, Gagnon JF, et al. Regional cerebral blood flow during wakeful rest in older subjects with mild to severe obstructive sleep apnea. Sleep 2015;38:1439-49.

23. Coloma Navarro R, Jiménez Caballero PE, Vega G, Ayo-Martin $\mathrm{O}$, Segura Martín T. Cerebral hemodynamics is altered in patients with sleep apnea/hypopnea syndrome. Springerplus 2016;5:51.

24. Hayreh SS. The blood supply of the optic nerve head and the evaluation of it - myth and reality. Prog Retin Eye Res 2001;20:563-93.

25. Hosking SL, Harris A, Chung HS, Jonescu-Cuypers CP, Kogemann L, Roff Hilton EJ, et al. Ocular haemodynamic responses to induced hypercapnia and hyperoxia in glaucoma. Br J Ophthalmol 2004;88:406-11.

26. Priou P, Gagnadoux F, Tesse A, Mastronardi ML, Agouni A, Meslier N, et al. Endothelial dysfunction and circulating microparticles from patients with obstructive sleep apnea. Am J Pathol 2010;177:974-83.

27. Moyal L, Blumen-Ohana E, Blumen M, Blatrix C, Chabolle F, Nordmann JP. Parafoveal and optic disc vessel density in patients with obstructive sleep apnea syndrome: an optical coherence tomography angiography study. Graefes Arch Clin Exp Ophthalmol 2018;256:1235-43.

28. Zhang J, Tan H, Shi X, Zheng X, Li Y, Li S, et al. [The effect of nasal continuous positive airway pressure on endothelial function in obstructive sleep apnea-hypopnea syndrome with coronary heart disease].[Article in Chinese]. Zhonghua nei ke za zhi 2006;45:188-91.

29. Wang JS, Xie HT, Jia Y, Zhang MC. Retinal nerve fiber layer thickness changes in obstructive sleep apnea syndrome: a systematic review and meta-analysis. Int $\mathrm{J}$ Ophthalmol 2016;9:1651-6.

30. Mammo Z, Heisler M, Balaratnasingam C, Lee S, Yu DY, Mackenzie P, et al. Quantitative optical coherence tomography angiography of radial peripapillary capillaries in glaucoma, glaucoma suspect, and normal eyes. Am J Opthalmol 2016;170:41-9

Received for publication: 24 April 2021. Accepted for publication: 14 July 2021.

This work is licensed under a Creative Commons Attribution-NonCommercial 4.0 International License (CC BY-NC 4.0).

(C) Copyright: the Author(s), 2021

Licensee PAGEPress, Italy

Multidisciplinary Respiratory Medicine 2021; 16:773

doi:10.4081/mrm.2021.773 